\title{
THE HARD WORK OF SOFTWARE HISTORY
}

A FEW YEARS AGO, the literary and media historian Friedrich Kittler opened an essay called "There Is No Software" with, in his own words, a "rather sad statement." In his view, "the bulk of written textsincluding this text-do not exist anymore in perceivable time and space but in a computer memory's transistor cells." From a scholar who, until then, had situated the cultural meaning of literary texts in discourse networks dependent on technologies of inscription (writing, gramophone, typewriter, computer) and the materiality of communication, this remark captures the essence of a significant cultural shift. At the end of the twentieth century, according to Kittler, texts-and even software itself-have vanished. Our text-producing gestures merely correspond to codes built on silicon and electrical impulses; the texts themselves no longer exist materially and, indeed, we have ceased to write them: "All code operations ... come down to absolutely local string manipulations and that is, I am afraid, to signifiers of voltage differences." ${ }^{1}$ Following Kittler, libraries and archives have yet to determine which traces have replaced the acts and artifacts of writing, such as books and manuscripts, that were part of Goethe's or Einstein's worlds at the conclusions of the previous two centuries.

About 10 years ago, the computer scientist Mark Weiser contributed an article titled "The Computer for the 21 st Century" to the Scientific 
American. Weiser's essay introduced his own research program to the magazine's technologically literate readership, a program he called "ubiquitous computing." The most startling observation in this article turned his vision of the future in an unexpected direction. According to Weiser, "the most profound technologies are those that disappear. They weave themselves into the fabric of everyday life until they are indistinguishable from it." In the first phase of computing, as he saw it, many people shared one large computer, such as a time-shared IBM mainframe, the Big Iron of the Information Age. Then with the advent of the microprocessor, computers became personal-one person, one machine. In his work at Xerox's Palo Alto Research Center until his premature death two years ago, Weiser-whose papers are now at Stanford-created small, portable, and networked devices for times in which computers would far outnumber people, the third age of ubiquitous computing. He believed it significant not that computers would outnumber us but, rather, that they would become invisible in order to be useful. As he put it a few years later, the "highest ideal is to make a computer so imbedded, so fitting, so natural, that we use it without even thinking about it." ${ }^{3}$ Indeed, he frequently referred to this third age as "the age of calm technology," meaning that in becoming omnipresent, computers also would become unremarkable.

The insights of Kittler and Weiser offer two versions of the disappearance of software in a world of computers. In this sense, they define the vanguard of writing about the cultural impact of software anno 2000. The notion that computers have taken over our lives has become fairly commonplace, but at a deeper level, Kittler and Weiser touch upon a source of malaise to some and exhilaration to others that future historians may regard as a fundamental aspect of our civilization - the notion

2. "The Computer for the 21st Century," Scientific American (1991). I am using the draft Weiser posted at URL: http://www.ubiq.com/hypertext/weiser/SciAmDraft3.html.

3. "Ubiquitous Computing." URL: http://www.ubiq.com/hypertext/weiser/UbiHome.html. 
that what is central is no longer the material, whether text or technology, but, rather, the imperceptible, the virtual, the invisible.

My topic today is the challenge these historians will face in documenting a cultural transformation that, by its very nature, has transformed the substance of historical documentation and radically altered the conditions of its preservation. For the most part, I will concentrate on the cultural medium of this transformation-software-and its history. By software, let it be understood that I am using the term loosely to include not just code and executable programs, but also digital media dependent on software and, at times, computing generally. I also will comment here and there on the changes that efforts to preserve the history of software may impose on institutions such as libraries, archives, and museums.

My Stanford colleague Tim Lenoir has written that he is "intrigued by the notion that we are on the verge of a new renaissance, that, like the Renaissance of the fourteenth and fifteenth centuries, is deeply connected with a revolution in information technology." He describes the transformation of our times as "heralding a posthuman era in which the human being becomes seamlessly articulated with the intelligent machine." Some of you in this audience might be more comfortable with the "printing revolution in early modern Europe," the title of Elizabeth Eisenstein's now-famous book, than you are with the notion that texts, technology, and even humanity have become dependent on, even integrated with, computer-based information technologies. On the other hand, who could be better situated to confront intellectual issues raised by profound transformations of media than historians of print and manuscript culture?

In my brief tour through some of the pitfalls and possibilities in building software history collections, I will begin with a short introduction 
on the history of software as a medium and describe a few of the characteristics of software that are likely to be important in historical perspective. From this wobbly ledge, I will dive into the turbulent problems that make it difficult to collect software. After drying off with a few examples of what has been accomplished despite the obstacles, I will finish this talk off with a cold shower by considering how providing access to these collections will raise organizational issues for archives, libraries, and museums.

\section{The History and Historiography of Software}

In light of the dependence of software on hardware, we should not be surprised that most histories of the software industry begin with their separation. ${ }^{5}$ The short version of this story takes off from the announcement by IBM in June 1969 that it would unbundle the provision of software from the sale or lease of its computer systems. In other words, until 1969, most software came bundled with computer hardware systems, the very industry dominated by IBM. Not that independently developed and marketed software was completely unknown, but it was limited largely to special-purpose applications or academic projects.

During the 1970s, the business, culture, and technology of software production changed dramatically. The industry grew rapidly after 1969. According to Martin Campbell-Kelly, sales of software in 1970 represented less than four percent of the entire computer industry. The volume of sales increased from this base more than twentyfold by 1982, fiftyfold by $1985 .{ }^{6}$ At about the same time, the term software engineering took hold to describe systems of software production based

5. Luanne Johnson, "A View from the Sixties: How the Software Industry Began," IEEE Annals of the History of Computing 20, no. 1 (1998): 36-42. Johnson's article provides a summary of this development.

6. Martin Campbell-Kelly, abstract of "Development and Structure of the International Software Industry, 1950-1990," Conference on "History of Software Engineering," Schloß Dagstuhl, Aug. 26-30, 1996. URL: http://www.dagstuhl.de/DATA/Reports/9635/campbellkelly.html. 
on theories and methods of computer science, stimulated by the first NATO Conference on Software Engineering in 1968. The proponents of software engineering applauded the establishment of computer science as a legitimate scientific field. The first academic departments in this new discipline were founded at institutions such as Purdue and Stanford in the early to mid-1960s; these new departments shifted the weight of attention to the study of software techniques, as opposed to the hardware engineering already sufficiently represented in electrical engineering and applied physics. Finally, also at the end of the 1960s, fundamental innovations in interface design and electrical engineering provided new platforms for changing the very meaning of computing in ways that redefined work on software. Douglas Engelbart's work at the Stanford Research Institute, for example, liberated the computer from its primary role as a calculating engine and headed it toward a future centered on information management and networked communications. The system designed at his Augmentation Research Center debuted spectacularly at the Fall Joint Computer Conference held in 1968 at the San Francisco Convention Center, just a few blocks from here, and inspired a generation of computer scientists to dream of new systems replete with mice, windows, icons, and desktops. Only a few months later, Stanley Mazor, Ted Hoff, and Federico Faggin designed the first single-chip central processing unit-a computer for all intents and purposes-which Intel introduced to the world as the 4004 microprocessor in 1971. A few years later, microprocessors made microcomputers possible, and soon after that, the personal computer took advantage of the capabilities of the new generation of software and computer interfaces.

Until these developments, the creation of software was inextricably tied to the relatively closed world of computer engineering. In time, the corporate world of Big Blue (IBM) gave way to the computers "for the rest of us," a change immortalized in the famous Macintosh Super 
Bowl television advertisement of 1984 . Writing on the history of software production lagged behind these changes, focusing, until recently, on the period from roughly 1945 to 1970 and thus for the most part following early hardware development. Paul Edwards, one of a new generation of historians of computing, sites the older historiography in what he calls the tradition of "machine calculation," while also locating a distinct set of writings and historical actors in the tradition of "machine logic" (software). The ancestry of this latter tradition, he argues, "lies in mathematics and formal logic." In his book on the "closed world" of Cold War computing, Edwards noted that the prevailing accounts within these internalist historiographies have rarely ventured beyond the perspectives of the scientists and engineers whose technical achievements defined them. Further, according to Edwards, "There is little place in such accounts for the influence of ideologies, intersections with popular culture, or political power."

\section{Change in the History of Software}

The changing industry, technology, and culture of computing from the 1970 s to the present redefined the aspirations of software designers and programmers. As historians have begun to come to grips with these changes, limitations in the historiography of "machine calculation" and "machine logic" have become more apparent. Wider, then widespread, access to computer technology has intensified interest in the social, cultural, and business history of computing, topics of no little importance for a historical social construction of software. The PC Revolution of the late 1970s and early 1980s revealed intersections among the contributions of computer scientists, software engineers, hobbyists, and entrepreneurs, connections implicit in the founding of influential organizations such as the Homebrew Computer Club and the People's

7. Paul Edwards, The Closed World: Computers and the Politics of Discourse in Cold War America (Cambridge, Mass.: MIT Pr., 1996). Quoted from excerpt of chapter 1 at URL: http:// www.si.umich.edu/ pne/cwpref.htm. 
Computer Company, or the title of Ted Nelson's Computer Lib/Dream Machines, first published in 1974. The work of Douglas Engelbart, Ted Nelson, Alan Kay, and others active in the 1960s and 1970s provided nourishing soil for the rapid development of software technology in the 1980s and beyond; examples include the role played by Nelson's hypertext in the creation of the World Wide Web, the influence of Engelbart's SRI lab and Kay's work at Xerox PARC on the development of graphical user interfaces such as those embedded in the Macintosh and Windows, and the many spin-offs of Cold War research in artificial intelligence and other problems for information technologies, such as library catalogs. An authoritative history of software since the late 1960s has not yet been written, but when it is, its author will face the task of synthesizing a rich and variegated history extending beyond the internal development of code, languages, and protocols.

\section{The Difficulties of Collecting Software}

These brief remarks on the history of software merely set the stage for considering the difficulties-some would say the impossibility-of collecting software. Archivists, librarians, curators, and historians face the daunting task of documenting these strands of software history and providing the source materials for studying them. In the first instance, this means considering how historians ten or a hundred years from now will reflect upon a ubiquitous, but invisible, technology. The emancipation of software production from the closed and bundled world of computer engineering since the 1970s has rapidly accelerated our dependence on software, increasing not only our interest in its historical development, but also our awareness of the evolving nature of information resources and storage. The new developments of the past quarter century, including personal computer technology, graphical interfaces, networking, productivity software, electronic entertainment, the Internet, and the Web have expanded the use of software and 
shifted the discourse of software history, while at the same time providing an astonishing potential wealth of electronic data for historical analysis. Yet, this potential has not come without a cost.

One of the most important changes future historians of the past 20 or 25 years will study is the dizzying rate of change in the uses of software for supporting new media of communication, entertainment, and information management. Recall that the research of Engelbart, Nelson, and others established the computer as a communication, rather than a calculation engine. This first-order expansion of the nature of software has been followed by convergences of media and software technology that will push software historians into nearly every medium of entertainment, art, storytelling, and information management. Software has become many things to many people, occupying the work, leisure, and creative time of millions of nonprogrammers as well as software designers.

The broader social and cultural impact of computing will revolutionize (if it has not already) all cultural and scholarly production. It follows that historians (not just of software and computing) will need to consider the implications of this change, and they will not be able to do it without access to our software technology and what we did with it. Software and digital information have begun to rival printed materials, visual media, and manuscripts as primary sources in many fields of inquiry, while writers, artists, musicians, game designers, and even historians work productively in the media of computing.

Often every trace of these activities, save our memory of them, has been born digital. Consider this simple example: I recently attended the conference of the Electronic Entertainment Exposition in Los Angeles as a session panelist. E3, as it is known, is the Mecca of computer-based entertainment, and it draws the digital generation, such as journalists, to a free lunch (which, in fact, is one of the attractions). Justin Hall, the 
organizer of my panel on the "Computer and Console Games-A Cultural Legacy?" told me that he already sold an article written the night before our panel to the highest bidder. He had been tapping away at his laptop and downloading images from his digital camera, but only after returning home did I discover that everything about this transaction, as well as his text, was now embedded in silicon, as Kittler might say. Hall has been keeping an online, Web-based diary continuously since 1994, "Justin's Links from the Underground," and after checking this site, I found this link, as we say, in his comments about the E3 article <The auction $>$. A moment's further browsing, and I found the article at salon.com. In other words, this article was written, photographed, sold, and published without a single "written" or paper trace. Of course, there are millions of similar examples of commerce, entertainment, authorship, artistic creation, journalism, science, and even software engineering carried out without paper. Each one adds to the urgency of software preservation, digital archiving, and accessible electronic libraries on a front far broader than the history of computing.

The relentless advance of computer technology on an ever-expanding set of fronts is redefining the nature and scope of computing itself. It could be argued, at least from the vantage of the present, that human beings interact directly with computers more than with any other technology. In many contemporary families, computers have partly replaced television sets, radios, and telephones. In The Road Ahead, published in 1995, Bill Gates provided a vision of the near future of computing that explicitly includes all "mediated experiences," whether of commerce of culture. ${ }^{8}$ Historians of software clearly will have to venture into every niche, nook, and cranny of society in ways that will separate their work from the work of other historians of science and technology. It has become far more difficult to locate the edges of computing as a discipline and to map the boundaries of its impact on

8. Gates, Bill. The Road Ahead. New York: Viking, 1995. 
society than for most other technical and scientific fields. The openended nature of computing challenges archivists, librarians, and curators, and it complicates matters for researchers looking for disparate materials in a variety of media and repositories.

So what do we do in the face of the growing volume, diversity, and importance of software? Part of the difficulty in defining next steps is that the very cat we are trying to put in the bag is ripping our heirloom luggage to shreds. This is perhaps where the history of software least resembles the history of print culture. This is not so much in the impermanence of its media-an issue upon which the dust has not yet settled-but, rather, in the flexibility of its use, with the capacity for converging previously separable realms concerned with what we now call "content": texts, stories, audiovisual experiences, interactive simulations, data processing, records management, and metadata applications such as indexing, among them. Traditional institutions and professional identities provide uncertain guidance in deciding who is responsible for the custodial care of software, given this diverse range of applications and associated knowledge. As Doron Swade points out from the perspective of a museum curator:

Some software is already bespoke: archivists and librarians have 'owned' certain categories of electronic 'document': Digitised source material, catalogues, indexes, and dictionaries, for example. But what are the responsibilities of a museum curator? Unless existing custodial protection can be extended to include software, the first step towards systematic acquisition will have faltered, and a justification for special provision will need to be articulated $a b$ initio in much the same way as film and sound archives emerged as distinct organisational entities outside the object-centred museum. ${ }^{9}$ 
Swade considers the problem as one of "preserving information in an object-centred culture," the title of his essay; that is, he ponders the relevance of artifact collections of software and the various methods of "bit-perfect" replication of their content. Libraries, and within libraries rare books and manuscript librarians, are coming to grips with related issues that might be described as "preserving information in a textcentred culture." In saying this, I realize that rare book and manuscript librarians are quite often the chief protectors of artifact-centered culture in American libraries. Nonetheless, their raison-d'être is the preservation of special categories of original source materials-primarily texts-for programs of academic research and teaching. This is one of the rubs in formulating institutional approaches to the preservation of software and related digital media, for software defines a new relationship between media objects and their content, one that calls into question notions of content preservation that privilege the original object. Current debates about the best methods for preserving software, which I have no intention of rehearsing here, are partly stuck on different institutional and professional allegiances to the preservation of objects, data migration, archival functions, evidentiary value, and information content. I fear that these issues are not likely to be sorted out before it is necessary to make serious commitments at least to the stabilization, if not the long-term preservation, of digital content and software.

\section{What Can Be Done? Some Projects and Programs}

Preservation of the records of software history has benefited from archival and historical work in other areas of recent science and technology. By the late 1970s, archival organizations, historical repositories, and professional societies had begun to pay systematic attention to their history. Disciplinary history centers such as the AIP History Center, the IEEE History Center, and the Charles Babbage Institute 
were established, in part, to coordinate and support the preservation of historical documentation and to work with existing repositories to address issues of archival appraisal, preservation, and access. In the early 1980s, the Society of American Archivists, History of Science Society, Society for the History of Technology, and the Association of Records Managers and Administrators cosponsored a Joint Committee on Archives of Science and Technology, known as JCAST. Its report, Understanding Progress as Process: Documentation of the History of Post-War Science and Technology in the United States, represented an important milestone when published in 1983, especially by raising awareness among American archivists of their need to understand better the records of postwar science and technology.

A loosely knit group of archival repositories and, just as important, an evolving set of principles and practices emerged out of archival research and projects such as the JCAST report. Guidelines for appraisal of records and documentation strategies set the stage for projects. By the late 1980s, the first published guides to collections in the history of computing appeared in print: Resources for the History of Computing, edited by Bruce Bruemmer, and The High-Technology Company: A Historical Research and Appraisal Guide by Bruce Bruemmer and Sheldon Hochheiser, both published by the Babbage Institute; and Archives of Data-Processing History: A Guide to Major U.S. Collections, edited by James Cortada and published by Greenwood Press. Together, they effectively document the strategies and programs that guided the growth of archival resources in the history of computing up to about 1990. Yet, it was clear that the work had only begun. Cortada noted that:

The first group of individuals to recognize a new subject area consists usually of participants followed closely after by students of the field and finally, if belatedly, by librarians and archivists. It is very frustrating to historians of a new subject, 
because it takes time for libraries to build collections or to amass documentary evidence to support significant historical research. This situation is clearly the case with the history of information processing. ${ }^{10}$

During these initial stages, the documentation of the history of computing was largely paper based. The founding of the archives of the Charles Babbage Institute at the University of Minnesota in 1979 (it had been founded at Stanford a few years earlier) was a signal event in this phase, as was the publication of a brochure on behalf of the History of Computing Committee of The American Federation of Information Processing Societies (AFIPS), called "Preserving Computer-Related Source Materials" and distributed at the National Computer Conference that year. The information in this brochure was based on earlier documentation efforts at the Center for the History of Physics of AIP. The brochure recommended that:

If we are to fully understand the process of computer and computing development as well as the end results, it is imperative that the following material be preserved: correspondence; working papers; unpublished reports; obsolete manuals; key program listings used to debug and improve important software; hardware and componentry engineering drawings; financial records; and associated documents and artifacts. ${ }^{11}$

It focused almost entirely on the preservation of paper records, even printouts, manuals, and text listings of programs, but nowhere mentioned the preservation of data files, merely noting with a nod to the museum value of hardware artifacts that "Actual computer componentry is also of great interest. The esthetic and sentimental value of such apparatus is great, but aside from this, the apparatus

10. James W. Cortada, "Preface," in Archives of Data-processing History: A Guide to Major U.S. Collections (New York: Greenwood, 1990), ix.

11. From the version provided by the Software History Center at: http:// www.softwarehistory.org/. 
provides a true picture of the mind of the past, in the same way as the furnishings of a preserved or restored house provide a picture of past society." 12

Even in the absence of a mandate to save software, libraries, archival repositories, and museums have mobilized resources to document the history of computing. Historians of software will draw on a variety of historical documentation that includes many formats, both digital and paper based. Because of the widening realm of software applications, hundreds, if not thousands, of repositories have saved collections touching on the history of computers and computing. Consider topics such as the history of hospital information management, library database technology, scientific computation, digital typography, or computer graphics in the film industry, topics for which documentation may be found in repositories ranging from government record centers and university archives to closed private collections and corporate records centers. The spectrum ranges from the Library of Congress to the Disney Archives, and as we shall see in a few moments, to virtual collections such as the Internet Archive.

Archives of Data-Processing History provided a good overview of the major repositories in the field circa 1990, and this circle has not widened considerably since that time, even though many collections have been added since then. The core group of brick-and-mortar collections consists of the Charles Babbage Institute, the Computer Museum (now the Computer History Center), the Hagley Museum and Library, the Library of Congress, the National Archives and Records Administration, the Smithsonian Institution, and the Stanford University Libraries, plus several corporate archives (IBM, AT\&T, Texas Instruments, and so on). Smaller, but nonetheless significant, collections can be 
found in university libraries and archives at Dartmouth, Harvard, MIT, Carnegie-Mellon, Illinois, and Pennsylvania as a consequence of the historical role of these institutions, rather than active collecting programs. In short, certainly fewer than ten institutions in the United States actively collect research materials in traditional formats for the history of computing. Growth since the early 1990s in available documentation has occurred largely as a result of independent, largely Webbased initiatives such as the RFC (Request for Comment) Index of key documents on the development of the Internet, private initiatives such as the Internet Archive, and numerous collections of digitized and born-digital materials assembled and accessible via online archives, home pages, and corporate Web sites. In a sense, a second generation of software archives has emerged in its own medium, creating a recursive problem concerned with the long-term preservation of these digital archives.

The Stanford University Libraries, where I have been curator of the history of science and technology collections since 1983, maintains an active archival program in the history of computing. Let me take a few minutes now to use our program as an example of how institutions go about acquiring collections of historical records relating to software. The library's program in the history of computing grew on two legs: first, an archival orientation in the narrow sense, focused on records of activities that took place at Stanford; and second, a collecting program founded in 1984 and called the Stanford and the Silicon Valley Project, today known as the Silicon Valley Archives. The idea behind the Silicon Valley Project was straightforward: Compile documentation tracing relationships connecting Stanford faculty and graduates to emerging high-technology industries in the surrounding region since the 1930s. It extended a flourishing program in the University Archives that, by the mid-1980s, had assembled collections of faculty papers and university records in the sciences and engineering. For software history, relevant 
collections in the University Archives include the papers of Ed Feigenbaum, John McCarthy, George and Alexandra Forsythe, Donald Knuth, and many others, as well as records of the Center for Information Technology (Stanford's computation center), the BALLOTS project papers (an early project in the area of library automation and database technology), the ACME Project collection (a collaboration of Edward Feigenbaum and Joshua Lederberg that led to path-breaking software in the field of expert systems such as MYCIN and DENDRAL), and the Heuristic Programming Project. As the Department of Computer Science, founded in 1965, has become perhaps the leading university program in its field, the University Archives has, by preserving records of its programs and faculty papers, grown in importance for the history of computing.

By 1984, it had become clear that the explosive growth of Silicon Valley not only dominated regional development, but that it was a forerunner of other highly concentrated techno-scientific regions. Because of the close connections between Stanford and specific business ventures located in Silicon Valley, the University Archives already owned significant collections relevant to its historical development. It was a logical step for the Department of Special Collections and University Archives to move forward and actively collect records of Silicon Valley enterprises and individuals not directly tied to Stanford. It appeared that no other institution would invest resources to locate and preserve archival materials documenting research and business growth characteristic of Silicon Valley industries. As a result of the decision to move forward with this program, Stanford has acquired substantial company and laboratory records, such as those of Fairchild Semiconductor Corporation, the American Association for Artificial Intelligence, the System Development Foundation, SRI Laboratories under the direction of Douglas Engelbart and Charles Rosen, and Apple Computer. After the parameters of our project had been established, we proceeded to work 
with faculty who were known to have contacts in Silicon Valley industry, such as Edward Feigenbaum and, more recently, Doug Brutlag. Another vector from Stanford out to Silicon Valley along the path of software, one of particular interest to this meeting, has been followed in digital typography, with the acquisition of the Euler Project papers of Hermann Zapf and the voluminous papers of Donald Knuth.

A new twist in the Silicon Valley Project has been the acquisition of software in various forms, accompanied by research projects that seek to tell the story of the Silicon Valley in its own medium. In the first instance, the libraries have acquired materials such as data tapes from Engelbart's ARC projects, hard-disk images along with collections of personal papers such as those of Jef Raskin and Mark Weiser, e-mail archives, streamed media and digitally taped audio and video interviews, electronic versions of student papers, and packaged commercial software, such as the Stephen F. Cabrinety Collection in the History of Microcomputing, which includes one of the world's largest collections of early computer and video games. Each of these formats requires special strategies for evaluating, recovering, stabilizing, possibly reformatting, and indexing content. In some cases, the strategies do not yet exist; in others, we have embarked on special projects to test techniques for ensuring that future historians will have access to their contents and creation. For example, in the case of computer game software, Tim Lenoir and I are heading a project called "How They Got Game: The History and Culture of Computer Games and Simulations," funded by the Stanford Humanities Laboratories. As part of this project, the results of which will be entirely Web based, we are evaluating a three-pronged approach to the documentation of game software: streamed video of game play, location and preservation of source code, and scanned images of related packaging, marketing materials, and documentation. Note that our efforts steer relatively clear of emulators, meta-data packaging, and the preservation of hardware, tech- 
niques currently at the center of contention among museum curators, archivists, and librarians about best practices for the long-term preservation of digital documents.

\section{Why Is Access to Software History Collections Difficult?}

Although I have certainly left out more topics than I have covered, I would like to conclude with a few remarks about the role of special collections in the preservation of software history. As we have seen, at both Stanford and other institutions, the archival impulse in the history of computing began with paper-based records and documentation. The printed guides cited earlier list the personal papers of computer scientists held in manuscript collections and archives, oral histories, and corporate records. Early computers have been saved by museums such as the Computer History Center and the Science Museum in London, and libraries have saved collections of documentation, technical reports, and the early computing literature. At Stanford, as elsewhere, manuscript, ephemera, and, to a lesser extent, book collections in the history of computing have landed in special collections and archives as an extension of earlier patterns of collecting practice. As the nature of this documentation shifts from paper to electromagnetic storage media, issues of access and technological complexity are calling this habit into question.

Access to software collections is the first problem. The mission of departments of special collections, especially in university libraries, includes not just preservation, but also satisfying the access requirements of users of these materials. Traditional models of access focused on the service desk and reading room as means of mediating complex systems of indexing and identification of materials, as well as supervised reading, fall apart in delivery contexts shaped by computer hardware and virtual libraries of born-digital materials. This is a problem not just for software history, but also for every field of cul- 
tural inquiry. Literary drafts, correspondence, graphics media, data, and images created in the 1990s are more likely to reside on disk or in networks than on paper, and the trend, as an optimistic stockbroker might say, is upward.

This issue of access to digital documents and software strikes me as urgently requiring new institutional and curatorial models. Let us consider again the divergent roles of archives, libraries, and museums. W. Boyd Raymond argues in an article on how electronic information is reshaping the roles of these institutions that "the functional differentiation of libraries, museums and archives as reflected in different institutional practices, physical locations, and the specialist work of professional cadres of personnel is a relatively recent phenomenon. This functional differentiation was a response to the exigencies of managing different kinds of collections as these have grown in size and have had to respond to the needs and interests of an ever enlarging body of actual and prospective users." Raymond's view is that individual scholars continue to favor the ideal of "personal cabinet of curiosities" finely tuned to specific research, an ideal that considers the format of artifacts and media as irrelevant, while stressing content. This was the "undifferentiated past" that these institutions hold in common. ${ }^{13}$

The often-synonymous usage of Special Collections and Rare Books and Manuscripts as designations of library programs will change as a result of collections of digital media and software. This will be a permanent change, and we cannot expect the traditional special collections community to come up with all the answers. One possibility is a kind of functional consolidation of media collections, digital libraries, and software archives. The creation of such cabinets of media curiosities would assemble specialists in curatorial domains

13. W. Boyd Raymond, "Electronic Information and the Functional Integration of Libraries, Museums, and Archives," in Electronic Information Resources and Historians: European Perspectives, ed. Seamus Ross and Edward Higgs (St. Katharinen, Germany: Scripta Mercaturae, 1993), 227-43, esp. 232. 
that are now separated, while cutting off the uncontrolled extension of established departments of special collections to digital materials and refocusing their attention on the venerated realms of rare books and manuscripts. Still, as Swade has noted in his writings on collecting software, it is tempting to lay aside theoretical problems of proper custody for software and worry, instead, about the work. The conundrum here is that while the relationship of software to hardware, its storage on physical media, or its association with artifacts such as disks, computers, and boxes, might lead one to think of software as fit for the museum, requirements of scholarly access such as identifying and locating sources, standards of indexing and meta-data creation, and maintenance of collections for retrieval and interpretation seem more in line with the capabilities and programs of libraries and archival repositories. In short, ad hoc decisions about curatorial responsibility may well have long-term implications for future scholarly work.

Kittler's admonition that "there is no software" provides little relief to archivists and librarians who discover that there is more of it than they can handle. And yet, the separation of physical media from content offers the glimmer of hope that the hard work of software history might be accomplished through a mixture of new organizational models, new technological skills, and established practices, as well as a reconvergence of museum, library, and archival curatorship. 